\title{
Una propuesta para una diferencia irreconciliable: la ejecución de laudos anulados y el principio de cortesía internacional
}

\author{
Alegría Jijón Andrade* \\ Adriana Orellana Ubidia** \\ Recibido/Received: 16/08/2019 \\ Aceptado/Accepted: 04/09/2019
}

Sumario: 1. Introducción y planteamiento del problema. 2. Los diferentes enfoques para tratar el dilema de la ejecución de laudos anulados 2.1 El enfoque tradicional. 2.2 El enfoque francés. 2.3 El enfoque de los Estándares Locales de Anulación. 3. Los laudos anulados en la sede sí pueden ser ejecutados: lo bueno y lo malo. 3.1 La Interpretación potestativa del artículo $\mathrm{V}$ es acorde al objeto y fin de la Convención de Nueva York. 3.2 La Corte de ejecución goza de una potestad discrecional para ejecutar el laudo anulado. 3.3 El laudo no depende de la ley de la sede para surtir efectos jurídicos. 3.4 El conflicto con el principio de cortesía internacional y la seguridad jurídica. 4. La propuesta: la carga de la prueba en caso de ejecutar laudos anulados.

Resumen: Ha existido un largo y sofistificado debate entre la comunidad internacional sobre la posibilidad de ejecutar

* Asociada en Pérez Bustamante \& Ponce. Abogada en España por la Universidad de Navarra, Abogada en Ecuador por la Universidad de los Hemisferios, Abogada en Nueva York y miembro de New York Bar Association. LL.M en Global Business Law en la Universidad de Nueva York, LL.M en Derecho Internacional Comparado en la Universidad Nacional de Singapur. Academic Visiting Reseacher en la Universidad de Harvard. Correo electrónico: ajijon@pbplaw.com

** Asociada en Pérez Bustamante \& Ponce. Abogada por la Universidad San Francisco de Quito. Candidata a LL.M. por la Universidad de Harvard. Correo electrónico: aorellana@pbplaw.com A. JiJÓn ANDRAdE \& A. ORellana Ubidia, "Una propuesta para una diferencia irreconciliable: la ejecución de laudos anulados y el principio de cortesía internacional", Revista Ecuatoriana de Arbitraje, No. 10, 2019, pp. 187-210. 
laudos arbitrales que han sido anulados desde el arbitraje. Diferentes países, incluso diferentes cortes del mismo país, han tomado decisiones distintas y contradictorias sobre este aspecto. El objetivo de este artículo no es resumir los distintos enfoques o decisiones judiciales relacionadas con este tema, pues consideramos que esta tarea ya se ha hecho en miles de artículos académicos, sino que proponemos un enfoque alternativo a la pregunta de si es que es posible y, de ser así, cómo podrían ejecutarse laudos arbitrales en un tercer Estado.

Palabras clave: arbitraje, laudo anulado, anulación, ejecución, jurisdicción primaria, jurisdicción secundaria, Convención de Nueva York, estándares de anulación.

\section{A proposal for an irreconcilable difference: the execution of annulled awards and the international courtesy principle}

Aвstract: There has been a long and sophisticated debate amongst the international community regarding the possibility of enforcing arbitral awards that have been vacated in the seat of the arbitration. Different countries, even different courts within the same country, have taken different and even contradictory decisions regarding this issue. The aim of this paper is not to summarize each of the different approaches or court decisions dealing with the subject, we believe this task has already been performed in a myriad of academic articles, but rather propose an alternative approach to the question of if and how could vacated arbitral awards could be enforced in a third state.

KeYworDs: arbitration, annulled award, annulment, enforcement, primary jurisdiction, secondary jurisdiction, New York Convention, annulment standards. 


\section{INTRODUCCIÓN Y PLANTEAMIENTO DEL PROBLEMA}

Este artículo no busca ser uno más sobre la ejecución de laudos anulados en la sede. Al contrario, este artículo busca proponer una solución que pueda armonizar los distintos principios que se contraponen al momento de la ejecución de un laudo anulado. Para ello, se pasará a analizar brevemente conceptos y principios fundamentales que se ven en conflicto al analizar esta problemática para luego buscar una respuesta que permita la ejecución de laudos anulados, sin transgredir principios de cortesía internacional o de la seguridad jurídica.

El laudo arbitral es una decisión de carácter inapelable e inimpugnable. Sin embargo, puede ser declarado nulo si no cumple determinados requisitos previstos en la ley de la sede del arbitraje ${ }^{1}$. La declaración de nulidad, como en todo proceso judicial, causa que el acto procesal deje de producir efectos y retrotrae el procedimiento hasta el momento en que ocurrió el vicio de nulidad". Es decir, aquel laudo "muere" luego de que las cortes del país de la sede del arbitraje confirman el vicio que padece.

Sin embargo, ¿qué sucede con el laudo que aparentemente ha muerto? ¿Cuáles son las consecuencias de esta declaración de nulidad?

Precisamente, la consecuencia más trascendental es que aquel laudo ya no podría ser ejecutado. El artículo V (1) (e) de la Convención de Nueva York, establece que entre los motivos que tiene una corte de ejecución para denegar la misma es que el laudo esté anulado. En efecto, este artículo dispone:

1. Sólo se podrá denegar el reconocimiento y la ejecución de la sentencia, a instancia de la parte contra la cual es invocada,

1. P. Lalive, “Absolute Finality of Arbitral Awards?”, Revista Internacional de Arbitragem e Conciliaçao, Ed. Almedina, p. 5.

2. F. Carnelutti, Sistema de Derecho Procesal Civil, 4ta Ed., 1994, p. 559. 
si esta parte prueba ante la autoridad competente del país en que se pide el reconocimiento y la ejecución [...]:

e) Que la sentencia no es aún obligatoria para las partes o ha sido anulada o suspendida por una autoridad competente del país en que, o conforme a cuya ley, ha sido dictada esa sentencia.

Ahora bien, la pregunta sobre si es posible el ejecutar laudos que han sido anulados en la sede del arbitraje es un problema de larga data, que sin embargo continúa presentándose de manera reiterativa en la actualidad. Sin embargo, el propósito de este artículo no es explicar la problemática a fondo, ya que esto ha sido explorado por incontables autores. El propósito de esta exposición es plantear una solución al problema de la ejecución de los laudos anulados y proponerla como alternativa para enfrentar el dilema.

Esta investigación comienza con un breve análisis sobre los distintos enfoques que la doctrina y la jurisprudencia le ha dado al dilema de la ejecución de laudos anulados [2]. Una vez expuestas estas teorías, se pasará a explicar las razones por las que se considera que un laudo anulado puede ser ejecutado, así como las consecuencias adversas que conllevaría la aplicación de esta teoría, con el propósito de extraer los principios fundamentales que se verían encontrados en este dilema [3]. Finalmente, se presentará la propuesta respecto de la carga de la prueba en los procesos de ejecución de los laudos anulados, con la cual se buscará conciliar los principios de soberanía y cortesía internacional, junto con la tendencia pro arbitraje [4].

\section{LOS DIFERENTES ENFOQUES PARA TRATAR EL DILEMA DE LA EJECUCIÓN DE LAUDOS ANULADOS}

La problemática en torno a la ejecución de laudos anulados ha acumulado una gran cantidad de doctrina que trata el tema 
en cuestión. Por ello, en esta sección se tratará de sintetizar aquellos enfoques con los cuales se concluye a favor o en contra de la ejecución del laudo anulado en la sede. Este breve resumen servirá luego para demostrar las raíces que sostienen las posturas tomadas en las siguientes secciones.

\subsection{El enfoque tradicional}

El enfoque tradicional consiste en considerar que un laudo pierde su fuerza vinculante cuando este es anulado y, por lo tanto, no se puede ejecutar en ninguna otra jurisdicción. Esta conclusión se deriva del efecto lógico de "inexistencia" que genera la declaratoria de nulidad del laudo, de manera que su fuerza vinculante desaparece. Así las cosas, es una consecuencia lógica que aquel laudo no pueda ser ejecutado en vista de que nada proviene de la nada o ex nihilo nil fit. En palabras de Albert JAN VAN DEN BERG, "una vez que el laudo ha sido anulado en el país donde se realizó, la adjudicación, ya no es elegible para el reconocimiento y la ejecución en los Estados contratantes" ${ }^{\prime \prime}$.

Otro argumento que sostiene la no ejecución de laudos anulados es que, siendo un laudo el producto de un sistema jurídico que está comprendido tanto por el derecho local como por las decisiones de los tribunales domésticos, las cortes de la sede del arbitraje son los órganos mejor dotados para decidir sobre la regularidad del arbitraje conllevado de conformidad con sus reglas 4 . En consecuencia, los tribunales de otros países deberían dar deferencia a la anulación por los tribunales del lugar del arbitraje y abstenerse de reconocer/ ejecutar los mismos ${ }^{5}$. En este sentido, Pieter SANDERS, uno de

3. A. J. Van Den Berg, "Enforcement of Awards Annulled in Russia", Journal of International Arbitration, 2010, pp. 179-198.

4. F. González De Cossío, Ejecución en México de laudos anulados en el extranjero, pp. 3-4, $<$ https://bit.ly/2lFYUOE $>(20 / 09 / 2019)$.

5. Ibídem. 
los participantes en la elaboración de la Convención de Nueva York, sostiene que las cortes de los países ejecutantes deben negarse ante la solicitud de ejecución de un laudo anulado dada su inexistencia 6 .

Este criterio ha sido también recogido por la Corte de Apelación del Distrito de Columbia, dentro del caso Termorio S.A.c. Electranta S.P., en el cual expresó:

Aceptar lo que los apelantes pretenden [refiriéndose al reconocimiento de un laudo anulado], sería menoscabar un precepto fundamental de la Convención de Nueva York: un laudo arbitral que no existe no puede ser ejecutado en otro de los países contratantes si es que este ha sido legalmente anulado por la autoridad competente en el Estado en el que fue dictado ${ }^{7}$.

Adicionalmente, en defensa del enfoque tradicional, se ha argumentado que las sentencias de anulación emitidas por los Tribunales de la sede del arbitraje producen efectos extraterritoriales que deben ser respetados en virtud de lo prescrito por la Convención de Nueva York y por el principio de reciprocidad internacional.

Primero, de acuerdo con la Convención de Nueva York, las cortes de la sede del arbitraje tienen competencia exclusiva para resolver sobre la validez de un laudo dictado en su territorio ${ }^{8}$. Este tema fue analizado en el caso Termorio S.A. c. Electranta S.P., en el cual se definen los conceptos de jurisdicción primaria y jurisdicción secundaria:

La Convención de Nueva York proporciona un marco cuidadosamente estructurado para la revisión y el

6. P. SANDERS, "New York Convention on the Recognition and Enforcement of Foreign Arbitral Awards", Netherlands International Law Review, 1959, p. 110.

7. Corte de Apelación del Distrito de Columbia, Termorio S.A. c. Electranta S.P., Caso No. 06$7058,25 / 05 / 2007$.

8. Corte de Apelaciones de Estados Unidos, Segundo Circuito, Yusuf Ahmed Alghanin \& Sons WLL c. Toys " $R$ " Us Inc., Caso No 1757, 10/09/1997; G. BorN, International Arbitration: Cases and Materials, Aspen Publishers Inc., 2011, p. 1119. 
cumplimiento de los laudos arbitrales internacionales. Solo un tribunal en un país con jurisdicción primaria sobre un laudo arbitral puede anular ese laudo. Los tribunales en otros países tienen jurisdicción secundaria; un tribunal en un país con jurisdicción secundaria se limita a decidir si el laudo puede ejecutarse en ese país. La Convención "ordena regímenes muy diferentes para la revisión de laudos arbitrales (1) en los [países] en los que, o según cuya ley, se ha otorgado el laudo, y (2) en otros [países] donde el reconocimiento y la ejecución son buscadas. Según la Convención, el país en el cual, o bajo la ley [de arbitraje] de la cual, [se] otorgó un laudo "se dice que tiene jurisdicción primaria sobre el laudo arbitral. Todos los demás estados signatarios son jurisdicciones secundarias, en las que las partes solo pueden impugnar si ese estado debe hacer cumplir el laudo arbitral'.

Consecuentemente, solo las cortes del país de la sede del arbitraje serán las competentes para emitir una sentencia de nulidad del laudo. Estas decisiones producen efectos extraterritoriales con la finalidad de evitar pronunciamientos contradictorios entre los distintos países signatarios ${ }^{10}$. Justamente, los Travaux Préparatoires de esta convención establecen que la finalidad de la extraterritorialidad de las sentencias es prevenir que los contratantes tengan que discutir su validez en cada país donde pretendan ejecutarlo ${ }^{11}$.

Segundo, por el principio de reciprocidad (Comity), los jueces de los Tribunales de ejecución deben reconocer los efectos erga omnes de las sentencias de anulación. De acuerdo con este principio del derecho internacional, un Estado soberano debe extender el reconocimiento de los actos judiciales de otro

9. Termorio S.A. c. Electranta S.P., N. 7.

10. Corte Distrital de Amsterdam, Nikolai Viktorovich c. OJSC Metallurgicheskiy Kombinat, Caso No 491569/KG, 11/11/2011; W. PARK, "Duty and Discretion in International Arbitration", The American Journal of International Law, 1999, p. 811; A. J. VAn Den Berg, N. 3, p. 191.

11. Consejo Económico y Social de las Naciones Unidas, Comité sobre la Ejecución de Laudos Internacionales, Summary Record of the Fourth Meeting E/AC.42/SR.4, 1955, p. 11; W. PARK, "Respecting the New York Convention", ICC International Court of Arbitration Bulletin, 2007, p. 72 . 
Estado en su territorio ${ }^{12}$. Por ejemplo, la Corte de Apelación para el Segundo Circuito de Estados Unidos, en el caso Baker Marine c. Cheoron, señaló que "en virtud de la Convención [de Nueva York] y del principio de cortesía internacional, no sería adecuado reconocer un laudo arbitral extranjero cuando este ha sido anulado por los tribunales competentes"13.

Por los motivos expuestos, la lógica de este enfoque radica en que un tribunal extranjero no puede "resucitar" un laudo que ha perdido su validez $\mathrm{y}$, por tanto, no podría tampoco ejecutarlo. Sin embargo, como se analizará a continuación, recientes teorías posibilitan aquello que el enfoque tradicional impide: la ejecución de un laudo anulado en la sede.

\subsection{El enfoque francés}

Los tribunales franceses, por su parte, han adoptado sistemáticamente la opinión contraria. Han entendido que, si un laudo es internacional, su existencia no debería verse afectada ni integrada con el marco legal local. Por lo tanto, han establecido que "un laudo de arbitraje anulado por la sede arbitral puede, no obstante, ser ejecutado en Francia si cumple con las normas francesas para ejecutar los laudos"14.

Esto fue planteado inicialmente a principios de los años 80 en el caso Société Pabalk Ticaret c. Société Norsolor. El laudo, emitido en Austria, fue parcialmente anulado por la Corte de Apelación de Viena por cuanto consideraron que los árbitros fallaron en equidad, a pesar de no haber estado facultados para ello, al haber aplicado la lex mercatoria ${ }^{15}$. La Corte de

12. M. Monroy Cabra, Derecho Procesal Civil Internacional, Librería del Profesional, 2000, p. 260.

13. Corte de Apelación de Estados Unidos, Segundo Circuito, Baker Marine Ltd. c. Chevron Ltd., Caso No. 97-9615, 12/08/1999.

14. C. Drahozal, "Enforcing vacated international arbitral awards: an economic approach", American Review of International Arbitration, Vol. 11, No. 4, 2000, p. 462.

15. Corte de Casación de París, Société Pabalk Ticaret Ltd. Sirketi c. Société Norsolor, 09/10/1984. 
Casación francesa reconoció la validez del laudo proferido en Austria y anulado a su vez por las cortes austriacas, y sostuvo que, con base en el artículo VII de la Convención de Nueva York, un juez no puede apoyarse en esa Convención para denegar el reconocimiento y ejecución de un laudo cuando su derecho nacional permita considerar ese laudo como válido y susceptible de ejecución ${ }^{16}$.

En este mismo sentido, el Tribunal de Apelación de París, en el caso República Árabe de Egipto c. Chromalloy Aeroservices, Inc, señaló:

El laudo otorgado en Egipto es un laudo internacional que, por definición, no está integrado en el ordenamiento jurídico de ese Estado, por lo que su existencia permanece establecida a pesar de haber sido anulado y su reconocimiento en Francia no es una violación de la política pública internacional ${ }^{17}$.

De esta manera, los tribunales franceses han rectificado esta posición en una serie de casos a lo largo de los años ${ }^{18}$. En todos ellos, los tribunales franceses ejecutaron los laudos que habían sido anulados en sus jurisdicciones de origen. La base legal para sostener esta postura se encuentra la ley nacional francesa sobre arbitraje internacional. Así, las cortes francesas afirman que aquella ley no podría considerarse como violatoria de la Convención de Nueva York ya que más bien facilita la ejecución de las sentencias extranjeras; por lo tanto, va más allá de la Convención y no en su contra.

16. F. Mantilla Serrano, "Algunos apuntes sobre la ejecución de los laudos anulados y la Convención de Nueva York", Revista Colombiana de Derecho Internacional, 2009, p, 22.

17. Corte de Apelación del Distrito de Columbia, República Árabe de Egipto c. Chromalloy Aeroservices Inc., Caso No. 94-2339, 31/07/1996.

18. Corte de Casación, Primera Sala de lo Civil, Pabalk Ticaret Ltd. Sirketi c. Norsolor S.A., Caso No. 83-11.355, 09/10/1984; Corte de Casación, Hilmarton Ltd. c. Omnium de Traitement et de Valorisation (OTV), Caso No. 92-15.137, 23/03/1994; Corte de Apelaciones de París, Direction Générale de l'Aviation Civile de l'Emirat de Dubai c. Internacional Bechtel CA París, 29/09/2005. 


\subsection{El enfoque de los Estándares Locales de Anulación}

El enfoque de los estándares locales de anulación (en adelante, LSA, por sus siglas en inglés), fue expuesto por primera vez por Jan PAulsson. Su tesis es que los laudos que han sido anulados bajo lo que élllama Local Standard Annulment no deberían dejar de ser válidos en países extranjeros, sino únicamente en el país donde aquellos estándares locales fueron aplicados. Sin embargo, aquellos laudos que han sido anulados sobre la base de la "anulación de estándar internacional" deben considerarse como una anulación que cae en el artículo V (1) (e) de la Convención.

La lógica de este enfoque es impecable, ¿por qué debería un LSA determinar los efectos de validez internacional de un laudo? Sin lugar a dudas, resulta irrazonable que una corte extranjera deba aplicar una sentencia de anulación en la cual se aplica un LSA como base para dejar sin efecto un laudo internacional. Por ejemplo, dentro del caso Termorio S.A. c. Electranta S.P. el motivo de anulación utilizado por el Consejo de Estado Colombiano fue que bajo ley colombiana no cabía el arbitraje administrado cuando (i) al momento en que las partes aceptaron los términos de referencia ya había cambiado la ley colombiana aceptando el arbitraje administrado, y (ii) ninguna de las partes había propuesto esta causal de nulidad ${ }^{19}$.

19. С. Косн, "The Enforcement of Awards Annulled in their Place of Origin The French and U.S. Experience“, Journal of International Arbitration, No. 26, 2009, pp. 267-292.

"Termorio seems to be typically one of those cases where a large arbitral award against the government, or one of its instrumentalities, issued in arbitral proceedings conducted in that state, is set aside by the courts of the seat on grounds which appear contrived. The Consejo de Estado (Council of State), the highest Colombian administrative court, vacated the award because, at the time that the ICC arbitration clause was entered into, Colombian law did not allow for the use of institutional arbitration. However, the parties signed the Terms of Reference without reservations at a time when Colombian law had been changed to allow for institutional arbitration. Under most circumstances, signing the Terms of Reference without reservations as to the validity of the arbitration agreement would remedy any initial defect in the agreement to arbitrate. Moreover, neither of the parties had raised this argument before the Colombian courts. It would thus seem that the Council of State was looking very hard for a reason to set aside the award. It therefore looks like the award was not judged on its merits but rather with a view to protect the interests of the state". 
Ahora bien, es claro que el rechazo de una sentencia de anulación extranjera, sea por los motivos que sea, puede causar un conflicto con el principio de cortesía entre países. Por ello, si bien este enfoque busca una solución en el tema de los estándares que deben ser tomados en cuenta para la anulación, esta propuesta no soluciona los potenciales problemas que se generan por la falta de atención al principio de cortesía internacional.

\section{Los LAUdos ANUlados EN LA SEDE Sí PUEDEN SER EJECUTADOS: LO BUENO Y LO MALO}

Una vez analizados brevemente los distintos enfoques, es posible concluir que los mismos no traen soluciones en cuanto al conflicto entre la cortesía internacional y la soberanía de las sentencias de nulidad de laudos. Por ello, antes de exponer la propuesta materia de esta investigación, se analizarán los beneficios y los problemas que la ejecución de laudos anulados puede acarrear en el escenario internacional, como lo es la vulneración del respeto a la soberanía del país sede del arbitraje, como la falta de aplicación del principio de cortesía internacional y la latente inseguridad jurídica que sentencias contradictorias podrían generar.

\subsection{La interpretación potestativa del artículo $\mathrm{V}$ es acorde al objeto y fin de la Convención de Nueva York}

El propósito de la Convención de Nueva York es hacer cumplir los laudos arbitrales internacionales, así como acrecentar la eficacia del arbitraje como medio de resolver las controversias de derecho privado ${ }^{20}$. Este propósito aparece también de la interpretación de los artículos de la Convención.

De acuerdo a su art. XVI, la Convención de Nueva York tiene cinco idiomas oficiales. Por esta razón, la aplicación

20. Convención sobre el Reconocimiento y la Ejecución de las Sentencias Arbitrales Extranjeras (1958), Art. II, p. 5. 
del art. V no es uniforme en todos los países signatarios. Por ejemplo, el texto de este artículo en francés es considerado imperativo -ne seront réfusés- mientras que el texto en inglés es potestativo -may refuse-21. En su versión en español se ha discutido cómo debe ser interpretada la palabra "podrá"; sin embargo, no se ha llegado a un consenso al respecto ${ }^{22}$.

Ante las diversas interpretaciones de textos igualmente auténticos de una convención, es preciso adoptar, de acuerdo a lo dispuesto por el art. 33.4 de la Convención de Viena sobre el Derecho de los Tratados, el sentido que mejor concilie esos textos, conforme al objeto y fin del tratado.

Por lo tanto, si el objetivo de la Convención de Nueva York es precisamente hacer cumplir los laudos arbitrales con la finalidad de convertir al Arbitraje en un medio más eficaz en el ámbito internacional, entonces el sentido que mejor conciliaría los textos idénticos, pero en diferentes idiomas, sería aquel dirigido a establecer una facultad potestativa a los jueces de las cortes de ejecución en cuanto a la ejecución o no de los laudos anulados por las causales referidas en el artículo $\mathrm{V}$ de la Convención de Nueva York. En consecuencia, la ejecución de laudos anulados en la sede es una forma de hacer prevalecer el objeto y fin de la Convención de Nueva York.

\subsection{La corte de ejecución goza de una potestad discrecional para ejecutar el laudo anulado}

Las cortes de ejecución de laudos internacionales poseen una potestad discrecional para ejecutar un laudo, a pesar que se configure una de las causales del art. V de la Convención

21. G. Born, International Commercial Arbitration. 2da Ed., Wolters Kluwer Law \& Business, p. 1121; J. Paulsson, "May or Must Under the New York Convention: An Exercise in Syntax and Linguistics", Arbitration International, Vol. 14, p. 227; W. M. ReISMAn, Systems of Control in International Adjudication and Arbitration, Duke University Press, p. 115.

22. G. Born, N. 21; J. Paulsson, N. 21, p. 229. 
de Nueva York. Las circunstancias enlistadas en el art. V de la Convención de Nueva York son de aplicación facultativa y excepcional para las cortes que conocen la solicitud de exequátur $^{23}$. Como se mencionó, el objetivo principal de la Convención de Nueva York es favorecer el reconocimiento y ejecución de laudos extranjeros y por ello presume la validez de los laudos ${ }^{24}$. El art. VII consagra este principio y otorga el derecho a que se reconozca un laudo conforme a la ley del lugar de ejecución cuando esta resulte más favorable ${ }^{25}$.

La aplicación facultativa de las causales del art. V de la Convención de Nueva York se evidencia por la expresión permisiva "se podrá denegar", que se extiende a todas sus causales $^{26}$. Esta expresión contrasta con el lenguaje imperativo empleado en otras disposiciones como "se aplicará" en el art. I, "reconocerá" en los arts. II y III o "deberá presentar" en el art. IV ${ }^{27}$.

Por ello, las cortes pueden ejecutar el laudo a pesar de que una de las partes demuestre la existencia de una de las causales $^{28}$. En este sentido se pronunció la Corte Suprema de Hong Kong en el caso China Nanhai c. Gee Tai. La demandada, Gee Tai, se opuso a la ejecución del laudo argumentando que el tribunal arbitral se constituyó irregularmente. Según su criterio, la causal se cumplió debido a que en su convenio arbitral las partes estipularon un arbitraje administrado por

23. Ibídem.

24. A. Mourre, "May or must? Las causales de no reconocimiento de los laudos previstas en el artículo V de la Convención de Nueva York, ¿Son ellas facultativas?”, en G. TAwIL \& E. ZulETA (Eds.), El Arbitraje Comercial Internacional: Estudio de la Convención de New York con motivo de su $50^{\circ}$ aniversario, Abeledo Perrot, p. 369.

25. P. SANDERs, "A Twenty Years Review of the Convention on the Recognition and Enforcement of Foreign Arbitral Awards", The lnternational Lawyer, Vol. 13, No. 2, 1979, p. 269.

26. L. Silberman \& M. Scherer, "Forum Shopping and Post-Award Judgments", PKU Transnational Law Review, Vol. 2, p. 116.

27. D. Jiménez Figueres, "Las Convenciones Anteriores a la Convención de Nueva York: Discusiones y Problemas", en G. TAwil \& E. Zuleta (Eds.), El Arbitraje Comercial Internacional: Estudio de la Convención de New York con motivo de su 50ªniversario, Abeledo Perrot, p. 11.

28. Alta Corte de Inglaterra y Gales, China Agribusiness Development Corporation c. Balli Trading, 20/01/1997. 
la CIETAC Shenzhen y en realidad lo administró la CIETAC Beijing. La Corte reconoció que la causal se cumplió y que, en principio, la CIETAC Shenzhen no era competente. No obstante, resolvió que su potestad para denegar la ejecución del laudo era discrecional. Por ello, al haberse cumplido el objetivo del convenio arbitral, que era la resolución de la controversia a través de un arbitraje administrado por la CIETAC, la Corte rechazó la pretensión de Gee Tai ${ }^{29}$.

En este mismo sentido, el caso Chromalloy Aeroservices c. República Árabe de Egipto, la Corte Distrital de los Estados Unidos para el Distrito de Columbia concluye que las cortes tienen la facultad de decidir la ejecución o no de un laudo. La única forma en la que se puede limitar la potestad discrecional para ejecutar un laudo es a través de una norma local, la cual los jueces de las Cortes de ejecución estarían obligados a respetar ${ }^{30}$.

A lo anterior debe sumarse que además de que las causales del art. V de la Convención de Nueva York son facultativas, son de aplicación excepcional. En efecto, en más del $90 \%$ de los casos a nivel mundial se ha concedido el reconocimiento y ejecución de los laudos a pesar de las objeciones presentadas con base en la Convención de Nueva York ${ }^{31}$.

\subsection{El laudo no depende de la ley de la sede para surtir efectos jurídicos}

A raíz de la entrada en vigencia de la Convención de Nueva York, la sede del arbitraje perdió cierta influencia

29. Ibídem.

30. Corte de Apelaciones de París, Ministère Tunisien de l'Equipement c. Société Bec Frères S.A, 1994; J. PAulsson, "Enforcing Arbitral Awards Notwithstanding Local Standard Annulments", Asia Pacific Law Review, p. 17.

31. G. Tawil \& E. Zuleta (Eds.), El Arbitraje Comercial Internacional: Estudio de la Convención de New York con motivo de su $50^{\circ}$ aniversario, Abeledo Perrot, XXVIII. 
sobre los laudos emitidos en ella ${ }^{32}$. Como consecuencia de ello, el tribunal de ejecución adquirió poderes de decisión más amplios para reconocer y ejecutar laudos anulados ${ }^{33}$. Esto se debe a que la tendencia internacional es favorecer la ejecución de los laudos internacionales ${ }^{34}$.

El principio a favor de la ejecución de los laudos anulados existe para contrarrestar los intentos de ciertos países de promover una actitud hostil hacia el arbitraje $\mathrm{e}^{35}$. Así se garantiza que laudos anulados por motivos puramente locales, como lo son políticas públicas locales o la revisión de los méritos por parte de las cortes, puedan ser ejecutados en el exterior y no se frustren los objetivos del arbitraje $\mathrm{e}^{36}$.

La fuerza vinculante de un laudo internacional no se deriva de un sistema legal específico, sino del convenio arbitral ${ }^{37}$. Al contrario, el carácter obligatorio del laudo proviene de la autonomía de la voluntad de las partes y de principios transnacionales, y no de la sede del arbitraje ${ }^{38}$. Por lo tanto, la anulación de un laudo en la sede no es motivo suficiente para desconocer el acuerdo válido de las partes para resolver sus controversias $^{39}$.

Por ejemplo, en el caso Societé Hilmarton Ltd. c. Societé Omnium de traitement et de valorisation, la Corte de Casación de Francia reconoció un laudo anulado en Suiza, país sede

32. D. Jiménez Figueres, N. 27, p. 10.

33. Ídem, p. 11.

34. J. M. Abascal, "Anulación de Laudos y sus Efectos", en, G. Tawil \& E. Zuleta (Eds.), El Arbitraje Comercial Internacional: Estudio de la Convención de New York con motivo de su 50 aniversario, Abeledo Perrot, p. 528.

35. G. Aceves Rivera, La Ejecución Internacional de Laudos Anulados en su País de Origen, Tesis ganadora del segundo lugar del premio J.C. Treviño, p. 13.

36. G. Aceves Rivera, N. 34; L. Silberman \& M. Scherer, N. 26, pp. 121-127.

37. Cámara de Comercio Internacional. Caso CCI No. 10623, 2003; J. PAulsson, "Arbitration Unbound: Award Detached from its Country of Origin", International and Comparative Law Quarterly, p. 368.

38. E. Gaillard, Teoría Jurídica del Arbitraje Internacional, Limusa, p. 45; P. Lastenouse, "Why Setting Aside an Arbitral Award is not Enough to Remove it from the International Scene", Journal of International Arbitration, p. 25.

39. Alta Corte de Inglaterra y Gales, Maximov c. Novolipetsky Steel Mill, 27/07/2017. 
del arbitraje. La Corte sostuvo que por tratarse de un laudo internacional no se encontraba vinculado al sistema legal de la sede. Consecuentemente, no se convirtió en inexistente por haber sido anulado al amparo de esta legislación.

Este enfoque permite que se cumpla uno de los objetivos del arbitraje internacional que es la existencia de un foro neutral distinto de una corte nacional ${ }^{40}$. Más aun, si un laudo dependiera enteramente de la sede, el fracaso de la petición de nulidad implicaría que las cortes del país de ejecución estén obligadas a reconocerlo y ello también es contrario a la discrecionalidad otorgada por la Convención de Nueva York ${ }^{41}$.

Incluso, la Convención de Nueva York le otorga mayor importancia al procedimiento de ejecución que al de nulidad ${ }^{42}$. Esto se evidencia en el art. VI que reconoce expresamente la facultad de las cortes de continuar la ejecución del laudo aunque esté pendiente la solicitud de anulación en la sede. Por todo lo expuesto, se llega a la conclusión que el laudo no depende de la ley de la sede para surtir sus efectos, pues es el carácter obligatorio del mismo deriva del acuerdo de las partes.

\subsection{El conflicto con el principio de cortesía internacional y la seguridad jurídica}

Ninguno de los argumentos anteriores permite dar una solución armoniosa respecto del conflicto que la ejecución de laudos anulados generaría con el principio de cortesía y respeto de la soberanía entre los países contratantes de la Convención de Nueva York.

Precisamente, casos como en el de Termorio S.A.c. Electranta S.P., se negó la ejecución en Estados Unidos de un laudo

40. L. Silberman \& M. Scherer, N. 26, p. 121.

41. P. Lastenouse, N. 41, p. 35.

42. A. Mourre, N. 24, p. 372. 
anulado en Colombia bajo el principio de comity, por lo que la corte de ejecución con respecto a si la decisión del Consejo de Estado Colombiano le merecía deferencia, concluyó que:

Para que nosotros avalemos lo que buscan los apelantes deberíamos socavar el principal precepto de la Convención de Nueva York: un laudo arbitral no puede ser ejecutado en otro Estado Contratante si ha sido "anulado" legalmente por una autoridad competente en el Estado en el que se realizó el laudo. Este principio es dispositivo en este caso. [...] El Consejo de Estado, el tribunal administrativo más alto de Colombia, es el expositor final del derecho colombiano, y no estamos en la posición de decir que la decisión de dicho tribunal es equivocada ${ }^{43}$.

Como resultado, se negó ejecución del laudo arbitral por haber sido anulado en la sede. El principio de comity o respeto internacional ha sido un eje fundamental del derecho internacional privado:

comitas gentium ob reciprocam utilitaten (cortesía internacional o recíproca utilidad). Esta posición es desarrollada por Huber cuya máxima es que, si los gobernadores de cada imperio admiten por cortesía las leyes de cada pueblo, en vigencia dentro de sus límites, tendrán vigencia en todas partes, siempre que no perjudiquen los poderes o derechos de otros gobiernos o de sus ciudadanos ${ }^{44}$.

Asimismo, al comity se lo ha definido como:

Cortesía internacional Doctrina y norma de conducta aplicada en el Derecho Internacional, según la cual las leyes de un Estado, no obstante su ineficacia extraterritorial, pueden recibir aplicación en un Estado distinto y en ciertos casos por atención, deferencia o benevolencia de esta hacia aquel, por razones de utilidad recíproca y por la esperanza de normas de reciprocidad ${ }^{45}$.

43. Termorio S.A. c. Electranta S.P., N. 7.

44. R. Contreras Horna, Derecho Internacional Privado, 1era Ed., Ediciones de la Universidad Los Ángeles, Chimbote, 2007, p.16.

45. M. Ossorio, Diccionario de Ciencias Jurídicas Políticas y Sociales, 1era Ed., p. 235. 
Incluso, se ha llegado a sostener respecto de este principio que:

[...] es necesario superar el principio de soberanía territorial en favor de la eficacia extraterritorial de las resoluciones judiciales y hacer valer en un Estado la solución que una autoridad judicial extranjera dio a un litigio de tráfico jurídico externo. [...] El principal mecanismo que el Derecho internacional privado conoce para garantizar la continuidad de las relaciones jurídicas, así como para asegurar la eficacia extraterritorial de una resolución, es el reconocimiento de la misma. El reconocimiento se configura como la aceptación por el Derecho del foro de que la resolución extranjera puso fin al objeto de la controversia. [...] el reconocimiento se enmarca en el principio general de cooperación internacional $[\ldots]^{46}$.

Sin embargo, existen varios y claros ejemplos de cortes alrededor del mundo que han decido ignorar decisiones judiciales de anulación de laudos de países extranjeros porque no pueden confiar en la parcialidad y legalidad de las mismas.

Por lo que no resulta en absoluto novedoso que cuando se duda de la legitimidad de una decisión judicial de un país de anulación, el resto de los países de la comunidad internacional decidan simple y llanamente ignorar la existencia de la misma y ejecutar el laudo anulado. Por ejemplo, una Corte de Florida estableció en el caso Comisa c. Pemex:

I hold [...] that the Eleventh Collegiate Court decision violated basic notions of justice in that it applied a law that was not in existence at the time the parties' contract was formed and left COMMISA without an apparent ability to litigate its claims. I therefore decline to defer to the Eleventh Collegiate Court's ruling, and I again confirm the Award and grant judgment thereon. (énfasis añadido) ${ }^{47}$.

46. M. Rodríguez Vázquez, Lecciones de Derecho Procesal Civil Internacional, p. 174.

47. Corte Distrital de Estados Unidos, Distrito del Sur de Nueva York, Corporación Mexicana de Mantenimiento Integral, $S$ de RL de CV ("Commisa") c. Pemex-Exploración y Producción, 27/08/2013. 
La Corte de Apelaciones de Ámsterdam llegó a una conclusión muy similar respecto de una sentencia dictada por las cortes de Rusia:

Considering (i) the [sic] 'close interwovenness' of Rosneft and the State of Russia; (ii) the several international indicators which referred to a) the lack of independence of the Russian judiciary, b) the fact that the judiciary receives instructions from the executive, (c) that the judiciary is used by the executive as a political instrument; and (iii) that partiality and dependency by their nature occur 'behind the scenes'; the Amsterdam Court of Appeals concluded that it is plausible that the award-annulment decision of the Russian Civil Court came from a partial process which lacked independence. Therefore, it did not deserve to be recognized in the Netherlands. (énfasis añadido $)^{48}$.

Otra corte en el Distrito de Columbia en el caso Chromalloy c. República Árabe de Egipto, enfatizó que las cortes extranjeras no están obligadas a respetar decisiones judiciales de otros estados soberanos, que el principio de reciprocidad y cooperación (comity) tiene límites, y específicamente si una decisión va en contra de su orden público o a la noción de justicia las demás cortes no tienen que considerar tal sentencia.

No nation is under an unremitting obligation to enforce foreign interests which are fundamentally prejudicial to those of the domestic forum. Laker Airways Ltd. v. Sabena, Belgian World Airlines, 731 F.2d 909, 937 (D.C.Cir.1984). "[C] omity never obligates a national forum to ignore the rights of its own citizens or of other persons who are under the protection of its laws." Id. at 942 (quoting Hilton v. Guyot, 159 U.S. 113, 164, 16 S. Ct. 139, 143-44, 40 L. Ed. 95 (1895) (énfasis parte del texto) ${ }^{49}$.

Ninguna de estas Cortes utilizó sus normas de derecho interno para ignorar las decisiones judiciales de otro país, al contrario, aplicaron normas y principios de derecho internacional, aplicables en todos los países. De hecho, en

48. Tercera Corte de Apelaciones de Ámsterdam, Yukos Capital SARL, c. Oao Rosneft, 28/04/2009.

49. República Árabe de Egipto c. Chromalloy Aeroservices Inc., N. 17. 
el mismo caso de Yukos c. Oao Rosneft, la corte holandesa expresamente estableció:

The question whether the decision of the Russian civil court to set aside the arbitral awards can be recognised in the Netherlands must be answered on the basis of the rules of general private international law (énfasis añadido) ${ }^{50}$.

Entre estos principios uno de los más importantes es el de orden público, mismo que si bien no tiene definición expresa en el Ecuador sí tiene reconocimiento legal y jurisprudencial ${ }^{51}$. Además, es importante recalcar, que el laudo internacional será objeto de mayor deferencia internacional que la Sentencia de nulidad, en tanto la mayoría de los países de la comunidad internacional son signatarios de la Convención de Nueva York que protege la ejecución de laudos mientras que no se puede decir lo mismo de las decisiones judiciales.

Adicional a lo anterior, una importante crítica práctica a este enfoque es que crea la posibilidad de juicios incongruentes $y$, por lo tanto, amenaza la seguridad jurídica y la armonización ${ }^{52}$.

\section{La propuesta: la carga de la prueba en caso de eJECUTAR LAUDOS ANULADOS}

Una vez analizado todo lo anterior, se intentará adaptar el razonamiento jurídico francés modificándolo para que pueda producir consecuencias más deseables. Nuestro enfoque propuesto es una mezcla del enfoque francés, el llamado enfoque de comity y la propuesta de LSA.

Como se mencionó, el objetivo principal de la Convención de Nueva York es favorecer el reconocimiento y ejecución de

50. Yukos Capital SARL, c. Oao Rosneft, N. 48.

51. Código Civil, Artículos 1477 y 1483. RO Sup No. 46 de 24/06/2005; Gaceta Judicial, Año CIII, Serie XVII, No. 10, 29/08/2002, entre otras.

52. M. HaRAvon, "Enforcement of Annulled Foreign Arbitral Awards: The French Supreme Court Confirms the Hilmarton Trend", Mealeys International Arbitration, Vol. 22, No. 9, 09/2007. 
laudos extranjeros y por ello presume la validez de los laudos ${ }^{53}$. Por esta razón, la carga de la prueba respecto de las causales del artículo $\mathrm{V}$ corresponde a quien busque la negativa en la ejecución de un laudo anulado. En este sentido, la carga de la prueba se encuentra invertida, pues el laudo goza de una presunción de validez.

La carga de la prueba es una noción procesal que contiene la regla de juicio, por medio de la cual se le indica al juez cómo debe fallar cuando no encuentre en el proceso pruebas que le den certeza sobre los hechos que deben fundamentar su decisión, e indirectamente establece a cuál de las partes le interesa la prueba de tales hechos, para evitarse las consecuencias desfavorables ${ }^{54}$.

Ahora bien, como se mencionó, la carga de la prueba generalmente corresponde a la parte que realiza una afirmación, pero para el caso de la ejecución de laudos internacionales, el ejecutante no necesita demostrar prima facie que el laudo es válido pues goza de aquella presunción. Precisamente, cuando un hecho goza de presunción legal está exento de prueba ${ }^{55}$. Por ello, la carga de la prueba se invierte y será la parte que pretenda denegar la ejecución quien deba demostrar que hay motivos de denegación.

La inversión de la carga de la prueba entraña un acto de responsabilidad tanto para el juzgador como para las partes, puesto que implica un juicio de valor acerca de quién está en mejores condiciones de probar, lo cual se relaciona directamente con la equidad, que es la justicia del caso concreto ${ }^{56}$. En el caso de la ejecución de laudos anulados, la Convención de Nueva York ha previsto que será la parte que pretende denegar la

53. A. Mourre, N. 24, p. 369.

54. D. Echandía, Teoría General de la Prueba Judicial, 5ta Ed., Tomo I, 1981, p. 426.

55. R. Herrera Vásquez, "La Inversión de la Carga de la Prueba: ¿Manifestación del 'In Dubio Pro Operario'?", Revista Themis, No. 18, p. 42.

56. G. Ferrer, Teoría General de la Prueba Judicial, 2003, p. 137. 
ejecución aquella en la mejor posibilidad de demostrar que el laudo no puede ser ejecutado.

Se ha alegado repetidamente que la carga de la prueba es uno de los elementos clave en la aplicación de la Convención. Matthew Sесомв hace un análisis muy interesante del artículo VI de la Convención, centrándose en quién necesita probar qué:

Se sostiene que a la luz de la política y el propósito del artículo VI, uno debería dar el beneficio de la duda a la corte en el lugar de origen y suponer que esa anulación sería una ISA. A la luz de esto, sería natural que la carga de probar que la naturaleza de la anulación fuera una LSA correspondería a la parte que busca la ejecución del laudo ${ }^{57}$.

En vista de lo anterior, y para lograr una armonía con el principio de cortesía internacional, resultaría más favorable para el sistema arbitral internacional que el fallo que anula el laudo en un país extranjero sirva como la mejor evidencia para el tribunal encargado de la ejecución. Así, las cortes de ejecución darían deferencia a aquellas decisiones. Hecho lo anterior, correspondería entonces al ejecutante demostrar que los motivos por los cuales se anuló el laudo no son aplicables en el país de ejecución por ser estos estándares locales de anulación (LSA), o que la anulación fue procesalmente injusta y que atenta contra los principios más fundamentales de justicia según el derecho internacional. Esto último respondería a una limitación al principio de cortesía internacional.

Claramente, esta propuesta no incluye una modificación de la Convención de Nueva York, lo cual sería una tarea hercúlea. Más bien en consonancia con el enfoque francés, consideramos que la convención solo establece la red de seguridad mínima para el reconocimiento de adjudicaciones

57. M. Sесомв, "Suspension of the Enforcement under Article VI of the New York Convention", Vindobona Journal of International Commercial Law and Arbitration, Vol. 5, pp. 1-8. 
extranjeras y, por lo tanto, los países siempre pueden adoptar estándares más favorables. Además, como vimos en el artículo $\mathrm{V}$ (1) los tribunales siguen siendo discrecionales para hacer cumplir los laudos, incluso si se cumple uno de los motivos de denegación.

Esta propuesta arrojaría consecuencias similares a lo que sucede con los laudos cuya ejecución se ha denegado en un país y la parte vencedora busca su cumplimiento en otro país. Por ejemplo, en Pavan S.R.L. C. Leng D'Or S.A., el tribunal reconoció que: "La Convención de Nueva York permite el reconocimiento en un estado y la negativa a reconocerlo en otro, como lo demuestran los motivos de denegación de la política pública"58. En este caso, el segundo tribunal no está obligado por el primer tribunal a negar la ejecución. Aún así, en la práctica, los tribunales han demostrado respeto y consideración por la decisión tomada por el primer tribunal.

Al dar a la decisión de la corte de la sede el estatus de la mejor evidencia se evitaría caer en la trampa VAN DEN BERG prevé:

Además, si los tribunales determinan por sí mismos qué anulación extranjera de un laudo arbitral es aceptable y cuál no, ellos no solo actúan violando la Convención de Nueva York, sino que también podrían encontrarse en un campo minado político. Al estigmatizar el sistema judicial de otro país, la relación política entre los países podría verse presionada.

Por lo expuesto, esta propuesta busca otorgar un peso mayor a la sentencia de nulidad del laudo, con la finalidad de saldar el conflicto con el principio de cortesía internacional y soberanía. Al mismo tiempo, no se limita a la parte que solicita la ejecución quien puede probar que la naturaleza

58. Juzgado de Primera Instancia e Instrucción de Rubí de España, Pavan S.R.L. c. Leng D'Or S.A., $11 / 06 / 2007$. 
de la anulación era una LSA. Asimismo, la parte que solicita la ejecución también puede probar que la anulación fue procesalmente injusta o que colisiona con principios fundamentales de justicia, incluso si el laudo fue anulado bajo una NIA. De esta manera la propuesta defiende el principio de la cortesía de las Naciones mientras se actúa en el espíritu de la Convención de Nueva York. 